CIRJE-F-1014

\title{
Indirect Taxes in the Cross-border Shopping Model: A Monopolistic Competition Approach
}

\author{
Hiroshi Aiura \\ Oita University \\ Hikaru Ogawa \\ The University of Tokyo
}

May 2016

CIRJE Discussion Papers can be downloaded without charge from:

http://www.cirje.e.u-tokyo.ac.jp/research/03research02dp.html

Discussion Papers are a series of manuscripts in their draft form. They are not intended for circulation or distribution except as indicated by the author. For that reason Discussion Papers may not be reproduced or distributed without the written consent of the author. 


\title{
Indirect Taxes in the Cross-border Shopping Model: A Monopolistic Competition Approach
}

\author{
Hiroshi Aiura \\ Faculty of Economics, Oita University, \\ 700 Dannoharu, Oita, 870-1192, Japan, \\ Tex/Fax: +81975547718, \\ h-aiura@oita-u.ac.jp \\ Hikaru Ogawa \\ Graduate School of Economics and Graduate School of Public Policy, \\ University of Tokyo, \\ 7-3-1 Hongo, Bunkyo-ku, Tokyo, 113-0033, Japan, \\ Tex/Fax: +81358415574/+81358415521, \\ ogawa@e.u-tokyo.ac.jp
}

\begin{abstract}
Within the framework of cross-border shopping with monopolistic competition, we examine the relative merits of an ad valorem (ADV) tax and a unit (specific) tax as indirect tax methods. Our study focuses on how the opening of borders and the entry of firms affect the equilibrium under each tax method. Our findings reveal that the ADV tax method is superior to the unit tax method in terms of tax revenue and welfare. In addition, while the entry of firms and opening of borders reduce the dominance of tax revenue under the ADV tax method, they increase the method's merits from a welfare perspective.
\end{abstract}

Keywords: monopolistic competition, spatial tax competition, unit (specific) tax, ad valorem tax.

JEL Classification Number. H21, H77, L13, R12 


\section{Introduction}

Traditional analyses suggest that an ad valorem (ADV) tax is welfare superior to a unit (specific) tax in a monopoly [Suits and Musgrave (1954)]. An ADV tax reduces monopoly power in a price-setting environment and, thus, transfers more revenue from the monopoly to the government. Researchers have since reexamined and substantiated this argument, focusing mainly on monopoly and oligopoly market structures. Most have confirmed that the superiority of an ADV tax still holds, although disagreements remain. ${ }^{1}$

Over the last 15 years, this research area has developed in at least two directions. First, departing from the short-run analysis in which the number of firms in the market is fixed, studies have also compared the two tax methods from the long-run equilibrium perspective. Under free entry/exit in the market in the long run, the short-run superiority of ADV taxes in the extracting firms' profit reduces entry incentives. Thus, the dominance of ADV taxes is challenged by a unit tax [Anderson et al. (2001a,b) and Schröder (2004)]. Models of monopolistic competition work more effectively when analyzing tax effects in a free entry/exit market because they accurately describe the circumstances in which short-run economic profit attracts new entrants in the long run. Of the monopolistic competition models, those of Schröder (2004), Dröge and Schröder (2009), Schröder and Sørensen (2010), and Vetter (2013) have emerged as popular approaches. ${ }^{2}$ Second, models have been extended from a single-country to a two-country framework. In most of the conventional literature, the tax methods are compared within a single-country framework in which consumers are forced to buy a domestic product irrespective of the level of prices and taxes. In contrast, more recent studies have considered cross-border shopping, trade, firm relocation, and capital mobility in a two-country model when analyzing the effects of a unit tax and an ADV tax [Lockwood and Wong (2000), Lockwood (2004), Jorgensen and Schröder (2005), Akai et al. (2011), Takatsuka (2013), Aiura and Ogawa (2013), and Akai et al. (2014)]. ${ }^{3}$

\footnotetext{
${ }^{1}$ For example, Delipalla and Keen (1992), Skeath and Trandel (1994), Myles (1996), Denicoló and Matteuzzei (2000), Anderson et al. (2001), and Blackorby and Murty (2007) examined non-equivalence of unit and ADV taxes in a monopoly and in an oligopoly. Furthermore, Kind et al. (2009) analyzed a two-sided market, while Hamilton (2009) and Lapan and Hennessy (2011) both analyzed a multiproduct market. See Keen (1998) for a general review of these studies.

${ }^{2}$ Schröder (2004) is the first to study tax effects under a Dixit-Stiglitz (1977) monopolistic competition and shows that the superiority of an ADV tax is retained. In a closed-economy version of the intra-industry trade model, Schröder and Sørensen (2010) demonstrate that the superiority of an ADV tax is not only preserved but reinforced through the intraindustry reallocation of firms. Vetter (2013) develops a model in which consumers spend some fixed proportion of their income on taxed goods and shows that ADV taxes are superior under oligopoly and monopolistic competition. However, the superiority of an ADV tax in a monopolistic competition market is challenged by Dröge and Schröder (2009), whose model includes environmental externalities. They demonstrate that a unit tax leads to higher welfare than an ADV tax does.

${ }^{3}$ Using a model of inter-regional capital tax competition, Lockwood (2004) and Akai et al. (2011) show that a unit tax is superior to an ADV tax and that selecting the unit tax method is a dominant strategy for governments. Lockwood and Wong (2000) compare the effects of a unit tax and an ADV tax in the tariff-war model and demonstrate the superiority of the ADV tariff. In contrast, by incorporating a protectionist trade policy, Jorgensen and Schröder (2005) show that a unit tariff generates a greater consumer surplus than an ADV tariff does, assuming that governments impose an import restriction. Takatsuka (2013) compares the effects of ADV and unit taxes on firm location within the framework of new
} 
Our aim in this study is to contribute to both directions of development. We construct a twocountry model in which consumers cross a border to buy a set of differentiated products provided in a monopolistically competitive market. The presence of cross-border shopping leads directly to standard inter-regional tax-cutting competition to attract consumers. In addition, because differentiated products are supplied in monopolistic competitive markets in both countries, the variety of products and thus the number of firms emerges as a source that attracts consumers. However, in the short run, the number of firms is fixed. Therefore, the government uses either a unit tax or an ADV tax simply to attract consumers by providing lower product prices. In the long run, with the free entry of firms, the tax choice affects the number of firms and the attractiveness of domestic products through lower prices, which together constitute the "total attraction" of a country. Under this setup, the main purpose of this study is to determine how the effects of the two tax methods differ in the short and long run in the presence of cross-border shopping behavior. Our model allows for cross-border shopping based on the work of Aiura and Ogawa (2013), who analyze the effects of a unit tax and an ADV tax in the short run (i.e., when the number of firms is exogenous). We later ease the assumption of a fixed number of firms (and thus the variety of products), allowing them to be determined endogenously in the long run. This enables us to clarify how the superiority of ADV taxes differs in the short and long run.

The results of the study can be summarized as follows. First, we find that an ADV tax is tax-revenue superior to a unit tax in a single country in a short-run equilibrium in which the number of firms is fixed even if we extend the model to a two-country framework with cross-border shopping. However, crossborder shopping behavior associated with border openings closes the tax revenue gap between ADV and unit taxes, which weakens the revenue superiority of an ADV tax. This is because when consumers cross the border, the reduction of the ADV tax rate accompanies consumer inflow from abroad. In addition to the effect that the tax cut boosts domestic demand, the border openings also provide incentives for all governments to set a lower ADV tax rate. A lower ADV tax rate reduces the tax revenue in equilibrium, which narrows the revenue gap between the ADV and unit taxes in the presence of cross-border shopping in turn. Second, we find that the tax revenue in an ADV tax competition remains greater than that in a unit tax competition in the long-run equilibrium in which all firms gain zero profit under free entry. This implies that an ADV tax dominates a unit tax not only in the short run but also in the long run. However, a comparison between short-run and long-run tax revenues reveals that the ADV tax method loses its advantage to some extent in the long run. In other words, the tax-revenue gap in the long run between the ADV and the unit tax is smaller than that in the short run. This is because the ADV tax method weakens the market power of the firms more compared with the unit tax method, which demotivates firm entry; thus, the number of firms under the ADV tax method is smaller than that under the unit tax

trade theory, although he does not compare the relative dominance of the two tax methods. Aiura and Ogawa (2013) compare the effects of a unit tax and ADV tax within the Hotelling-type spatial competition. They show that governments are committed to the ADV tax method but that the choice leads to inferior outcomes. The recent study of Akai et al. (2014) shows that each government chooses a unit subsidy as a dominant strategy, which may justify the assumption of unit subsidies in the series of third-country models developed by Brander and Spencer (1985). 
method in the long-run equilibrium. Because mobile consumers benefit from both lower tax rates and "variety," in the long run, a government using an ADV tax method has an incentive to lower its tax rate compared with one using a unit tax method. In in the short run, however, a government does not have such an incentive because the number of firms is fixed. Thus, it chooses a lower ADV tax rate in the long run than it does in the short run. This leads to our finding that the tax-revenue gap between an ADV tax and the unit tax is smaller in the long run, showing that the entry of firms weakens the tax-revenue superiority of the ADV tax method. Finally, we also examine the effects of cross-border shopping by comparing a closed-border economy to an open-border one. Here, we find that once consumers can cross the border owing to reduced transport costs, the tax-revenue gap between ADV tax competition and unit tax competition decreases.

We examine the robustness of our results in the second part of the paper by presenting a model of a welfare-maximizing government. Here, the results show that governments now subsidize firms to invite consumers and firm entry. In this case, the ADV tax is welfare-superior to the unit tax in the long run, while the two methods are welfare-indifferent in the short run. This implies that the entry of firms strengthens the superiority of the ADV method from a welfare perspective, which contrasts with the finding in the case of a revenue-maximizing government in which the superiority of the ADV tax is reduced with the entry of firms. We also clarify the effects of cross-border shopping. When consumers can cross the border, the welfare gap between ADV tax competition and unit tax competition is unchanged in the short run but increases the welfare gap in the long run.

The remainder of this paper is organized as follows. In section 2 , we set up the basic model. In section 3, the tax effects are analyzed. The first part of this section presents the tax effects on the short-run equilibrium in which the number of firms (or varieties) is fixed. The second part analyzes tax effects on the long-run, free-entry equilibrium. Section 4 presents an extension of the model to study the outcome using an alternative government objective, and section 5 discusses how the equilibrium values are modified with the government's objective. Section 6 concludes.

\section{Model}

\subsection{Technology and preferences}

The basic Hotelling model with differentiated products follows the work of Henkel et al. (2000). A line economy consists of two symmetric countries, $j=1,2$. The location space of the economy is given by $\theta \in[-1,1]$ divided into two countries at $\theta=0$, the length of each country, and is therefore $1 . \theta=0$ is the exact middle of this economy, so consumers to its left are residents in country 1 while consumers to its right are residents in country 2. A continuum of consumers is uniformly distributed along the line. In each country, there is a retail product market of monopolistic competition at the end of the line. ${ }^{4}$

\footnotetext{
${ }^{4}$ As long as the location is symmetric and exogenous, the assumption that a retail product market is located at the end of the line is not crucial. For instance, if the market is located at the center of each country, the firms in the retail product
} 
The retail product sector $(s=M)$ consists of a continuum of firms producing differentiated products under an increasing-returns-to-scale (IRS) technology in a monopolistic competition market. The standard homogeneous goods sector $(s=H)$ produces a homogenous product under a constant-returnsto-scale (CRS) technology in a perfectly competitive market.

The firms in the retail product sector, $M$, are fixed at their locations. Consumers shop for the set of differentiated retail products at either market and bear the transport cost (i.e., traveling expenses) to the market.

Technology. Homogeneous goods are produced using only labor and under perfect competition. Firms in this sector produce one unit of a homogeneous good from one unit of labor in every location. Therefore, in the homogeneous goods sector, goods are priced at the wage rate, and the shipment of goods incurs no transport costs. Because we assume that the homogeneous goods are the numeraire, the wage rate is unity.

In the retail product sector, firms produce products with the IRS technology under monopolistic competition. Because each firm produces one variety, the number of firms coincides with the number of varieties. The production of any variety incurs $f$ units of fixed cost and $c$ units of marginal cost. The number of varieties produced in a country, $j$, is denoted by the continuous variable $n_{j}$. The variety $i$ produced in country 1 is homogenous with the variety $i$ produced in country 2 . This implies that consumers are able to consume a wider variety of products in country $j$ if $n_{j} \geq n_{k}(k \neq j)$. Then, $p_{j}(i)$ denotes the price of variety $i$ supplied in country $j$.

Preferences. Preferences are assumed to be identical across consumers and are characterized by a quasilinear utility function over homogeneous goods produced by sector $H$ and differentiated goods produced by retail product sector $M$. The utility function is identical for all consumers located at any point $x \in[0,1]$ and is given as $U(x)=H+\mu \ln M$, where $M$ is the sub-utility derived from consuming varieties of differentiated products and $H$ is the consumption of homogeneous goods. If a consumer goes to country $j$ to consume a set of differentiated goods, the sub-utility $M$ is given by

$$
M=M_{j}=\left[\int_{0}^{n_{j}} m_{j}(i)^{(\sigma-1) / \sigma} d i\right]^{\sigma /(\sigma-1)},
$$

where $m_{j}(i)$ is the amount of consumption of variety $i$ in country $j$ and $\sigma>1$ is the elasticity of substitution between any two products. The budget constraint of a consumer living at point $x \in[-1,1]$ who buys the differentiated products from the firms in country $j$ is given as follows.

$$
I=H+\int_{0}^{n_{j}} p_{j}(i) m_{j}(i) d i+F_{j}(x),
$$

where $F_{1}(x)=\tau(1+x)$ and $F_{2}(x)=\tau(1-x) .{ }^{5}$ Here, $\tau(>0)$ denotes the transport cost per unit distance. market simply compete for consumers located at somewhat short intervals.

${ }^{5}$ For example, consider a consumer of country 1 who lives at point $x=-0.5$. If he goes to the market in country 1, (2) becomes $I=H+\int_{0}^{n_{1}} p_{1}(i) m_{1}(i) d i+\tau(1-0.5)$, while if he goes to the market in country 2 , it becomes $I=$ $H+\int_{0}^{n_{2}} p_{2}(i) m_{2}(i) d i+\tau(1+0.5)$. 
In (2), $I$ is the income and $F_{j}(x)$ is the transportation cost when traveling to the market in country $j$. Because variety $i$ in one country is homogeneous with variety $i$ supplied in the other country and consumers bear the transport cost of traveling to these markets, they buy the differentiated products from either country 1 or country 2 .

Government objective. In each country, there is a single tax-revenue-maximizing government that raises revenue only through taxes on differentiated products. ${ }^{6}$ The government uses either the unit tax or the ADV tax method and chooses the tax level. If the government adopts the unit tax method, taxes are imposed on the number of units sold. If it selects the ADV tax method, taxes are imposed on the amount of sales.

\subsection{Utility maximization}

Consider first that a consumer living at point $x$ decides to buy differentiated products from country $j$. Then, solving the utility maximization problem of the consumer, we have the following demand function.

$$
m_{j}(i)=\frac{p_{j}(i)^{-\sigma}}{P_{j}^{1-\sigma}} \mu \text { and } H=I-\mu-F_{j}(x)
$$

where

$$
P_{j}=\left(\int_{0}^{n_{j}} p_{j}(i)^{(1-\sigma)} d i\right)^{1 /(1-\sigma)} .
$$

Using (3), the indirect utility function of an individual located at point $x$ who goes to country $j$ to shop for differentiated products can be obtained as

$$
U_{j}(x)=I-\mu+\mu \ln M_{j}-F_{j}(x) .
$$

When $U_{1}\left(x^{*}\right)=U_{2}\left(x^{*}\right)$, the consumer who locates at $x^{*}$ is indifferent between consuming in one country or the other. In this case, to buy differentiated products, all consumers located to the left of $x^{*}$ would go to country 1 and all consumers located to the right of $x^{*}$ would go to country 2 . Hence, the number of consumers who buy differentiated products from the market in country $j, l_{j}$, is given by

$$
l_{j}\left(M_{j}, M_{k}\right)=1+\frac{\mu}{2 \tau}\left(\ln M_{j}-\ln M_{k}\right),
$$

where $j=1,2, j \neq k$. Because $M_{j}$ includes the number of firms and prices, mobile consumers are attracted by the product varieties and lower prices.

\footnotetext{
${ }^{6}$ We follow the literature (e.g., Schröder (2004), Dröge and Schröder (2009), and Schröder and Sørensen (2010)) in assuming that the products in the homogeneous goods sector, $H$, are not taxed, which makes the analysis tractable. Takatsuka (2013) confirms that extending the tax to the products in both sectors complicates the analysis but does not induce something in return. We also follow standard spatial tax competition models (e.g., Kanbur and Keen (1993), Ohsawa (1999), Wang (1999), and Aiura and Ogawa (2013)) in assuming that the governments are revenue-maximizing and defer discussions on an alternative objective function to later.
} 


\section{$2.3 \quad$ Firms}

Denoting the ADV tax rate of country $j$ as $r_{j}$ and the unit tax rate as $t_{j}$, each firm maximizes its profit as

$$
\pi_{j}=\left[\left(1-r_{j}\right) p_{j}(i)-\left(c+t_{j}\right)\right] m_{j}(i) l_{j}\left(M_{j}, M_{k}\right)-f
$$

where $m_{j}(i)$ is given by (3). Under monopolistic competition, each firm takes the prices charged by its rivals as given and ignores the impact of its price change on the market variables. Therefore, $\partial P_{j} / \partial p_{j}(i)=$ 0 and $\partial M_{j} / \partial p_{j}(i)=0$. Hence, profit maximization yields

$$
p_{j}(i)=p_{j}=\frac{\sigma\left(c+t_{j}\right)}{(\sigma-1)\left(1-r_{j}\right)} .
$$

Substituting (6) into (5), the firm profit in country $j$ is

$$
\pi_{j}=\frac{\left(1-r_{j}\right) \mu}{n_{j} \sigma} l_{j}-f .
$$

In (7), from (1), (3), (4), and $(6), l_{j}\left(r_{j}, r_{k}, t_{j}, t_{k}, n_{j}, n_{k}\right)$ is given by

$$
\begin{aligned}
l_{j} & =1-\frac{\mu\left[\ln p_{j}\left(r_{j}, t_{j}\right)-\ln p_{k}\left(r_{k}, t_{k}\right)\right]}{2 \tau}+\frac{\mu\left(\ln n_{j}-\ln n_{k}\right)}{2 \tau(\sigma-1)} \\
& =1+\frac{\mu\left[\ln \left(1-r_{j}\right)-\ln \left(1-r_{k}\right)\right]}{2 \tau}-\frac{\mu\left[\ln \left(c+t_{j}\right)-\ln \left(c+t_{k}\right)\right]}{2 \tau}+\frac{\mu\left(\ln n_{j}-\ln n_{k}\right)}{2 \tau(\sigma-1)},
\end{aligned}
$$

where $j=1,2$ and $j \neq k$. The second and third terms in (8) capture consumers' mobility owing to the inter-regional price gap that originated from the tax gap between the two countries. The fourth term reflects the fact that consumers are attracted to the country with a greater variety of differentiated products. These three terms become more important as transport costs decrease. In addition, the fourth term is more important in the economy in which $\sigma$ is small, as consumers are increasingly attracted to the country with a greater variety when the elasticity of substitution between any differentiated products is small.

Because the long-run profit for monopolistic competitors is zero owing to free entry and exit, the long-run equilibrium condition satisfies $\pi_{j}=0$. Therefore, the equilibrium number of firms (varieties) is

$$
n_{j}=\frac{\left(1-r_{j}\right) \mu}{\sigma f} l_{j}
$$

Using (3), (6), and (9), the demand for variety $i$ in country $j$ is given by

$$
m_{j}(i)=\frac{\mu}{n_{j} p_{j}}=\frac{(\sigma-1) f l_{j}}{\left(c+t_{j}\right)} .
$$

The equilibrium values of $l_{j}$ and $n_{j}$ satisfy (8) and (9), which are implicitly obtained as a function of tax rates:

$$
\begin{aligned}
l_{j} & =l_{j}\left(r_{j}, r_{k}, t_{j}, t_{k}\right), \\
n_{j} & =n_{j}\left(r_{j}, r_{k}, t_{j}, t_{k}\right),
\end{aligned}
$$


where $j \neq k$. Substituting (11) into (10), we implicitly obtain the equilibrium consumption of variety $i$ in country $j, m_{j}(i)$, as the function of the tax rates. The explicit solutions are obtained by inserting the equilibrium tax rates shown in the subsequent analysis.

Here, we mention the differences of the tax effects between our model and that of Dröge and Schröder (2009). Suppose that consumers do not cross the border to shop for differentiated products (i.e., $l_{j}$ is fixed at 1). Then, (9) and (10) show that an increase in the ADV tax rate reduces the number of firms but has no effect on the demand for each product. In contrast, (9) and (10) suggest that an increase in the unit tax has no effect on the number of firms but decreases the demand for each product. The latter feature slightly differs from the result obtained by Dröge and Schröder (2009). In Proposition 1 of their analysis, they show that an increase in the unit tax increases the number of firms but decreases product demand. The difference in the findings stems from the assumption of the utility function. Dröge and Schröder (2009) assumed a Cobb-Douglas utility function. Thus, the lump-sum transfer financed by the tax policy accompanies the income effect, increasing the total demand for differentiated products. In our model, the tax revenue is used for government purposes and is not distributed to residents. Even if the tax revenue is returned to the residents in a lump sum, it has no effect on the total demand for differentiated products because our model assumes a quasi-linear utility function with no income effects.

\subsection{Governments}

When the government in country $j$ uses a unit tax, using (6) and (10) with $r_{j}=0$, the tax revenue, $R_{j}^{U}=t_{j} m_{j} n_{j} l_{j}$, is given by

$$
R_{j}^{U}=\frac{t_{j}}{p_{j}} \mu l_{j}=\frac{\mu(\sigma-1)}{\sigma} \cdot \frac{t_{j}}{c+t_{j}} l_{j},
$$

where $l_{j}$ is given by (11). In (13), superscript $U$ denotes the choice of the unit tax method. On the other hand, using (6) and (10) with $t_{j}=0$, the tax revenue of the government in country $j$ when it imposes an $\mathrm{ADV}$ tax, $R_{j}^{A}=r_{j} p_{j} m_{j} n_{j} l_{j}$, becomes

$$
R_{j}^{A}=\mu r_{j} l_{j},
$$

where superscript $A$ denotes the choice of an ADV tax. $l_{j}$ in (14) is again given by (11).

In the next section, we analyze the equilibrium characteristics when both governments maximize their tax revenue using either a unit tax or an ADV tax.

\section{Tax-revenue Maximization}

Subsection 3.1 presents a benchmark model in which transport costs are sufficiently high to deter crossborder shopping, which is interpreted as a closed-border economy. ${ }^{7}$ Subsections 3.2 and 3.3 analyze the

\footnotetext{
${ }^{7}$ In fact, we assume that the transportation cost is sufficiently small to cover domestic markets both in a closed and open economy. Therefore, when we examine the closed-border economy case, we suppose that the transportation cost is
} 
equilibrium characteristics when both governments compete for mobile consumers using different tax methods. Specifically, subsection 3.2 presents the short-run analysis, in which the number of firms (and thereby the variety of products) is fixed. To focus on a symmetric equilibrium, the number of firms in each country is fixed at the same level. In subsection 3.3, we present the long-run analysis in which firms are allowed to enter/exit. In both subsections, we first present the outcome when the governments employ a unit tax and then the outcome when they use the ADV tax method. In subsection 3.4, we study the impacts of border openings in both the short and long run.

\subsection{Benchmark: Closed-border economy}

When there is no cross-border shopping, we have $l_{1}=l_{2}=1, d l_{j} / d t_{j}=0$, and $d l_{j} / d r_{j}=0$. In this case, from (13) and (14), the tax revenue increases as the tax rate increases. Then, the maximum tax revenues in the case of a unit tax and an ADV tax become

$$
\max _{t_{j}} R_{j}^{U}=\lim _{t_{j} \rightarrow \infty} R_{j}^{U}=\frac{\sigma-1}{\sigma} \mu \text { and } \max _{r_{j}} R_{j}^{A}=\lim _{r_{j} \rightarrow 1} R_{j}^{A}=\mu>\max _{t_{j}} R_{j}^{U} .
$$

We denote the maximum tax revenue under a unit tax and an ADV tax in the short-run, closed-border economy as $\hat{R}^{U C}$ and $\hat{R}^{A C}$, respectively, where superscript $C$ denotes the closed-border economy and a hat represents the equilibrium value in the short run. The subscript is omitted because we derive the value of a symmetric equilibrium. A comparison shows that

$$
\hat{R}^{A C}-\hat{R}^{U C}=\mu-\frac{\sigma-1}{\sigma} \mu>0 .
$$

The inequality in (15) confirms the standard argument that the ADV tax revenue is greater than the unit tax revenue [Suits and Musgrave (1953)]. The ADV tax method lowers firms' ability to control the price of their products in monopolistic competition and thus transfers more revenue from the monopolistically competitive firms to the government.

Furthermore, when the border is closed, the maximum tax revenue under a unit tax and an ADV tax in the long-run equilibrium is identical to that in the short-run equilibrium. Therefore, $\hat{R}^{U C}=\tilde{R}^{U C}$ and $\hat{R}^{A C}=\tilde{R}^{A C}$, where a tilde denotes the equilibrium value in the long run. This is because the tax revenues represented by (13) and (14) do not depend on the number of firms in the closed-border economy, $n_{i}$, in which $l_{1}=l_{2}$ holds. Hence, we have

$$
\tilde{R}^{A C}-\tilde{R}^{U C}=\mu-\frac{\sigma-1}{\sigma} \mu>0 .
$$

From (15) and (16), we have the following result.

Proposition 1. When consumers do not cross the border, (i) the ADV tax revenue is always greater than the unit tax revenue, $\hat{R}^{A C}>\hat{R}^{U C}$ and $\tilde{R}^{A C}>\tilde{R}^{U C}$, and (ii) the tax revenue gap between the medium-sized, in which cross-border shopping is deterred but both domestic markets are fully covered. Alternatively, we may assume in the closed-border economy that there are some trade barriers to deter cross-border shopping that keep transportation costs low. We thank an anonymous referee for pointing out this alternative view. 
$A D V$ tax and the unit tax in the short run is the same as that in the long run, namely, $\hat{R}^{A C}-\hat{R}^{U C}=$ $\tilde{R}^{A C}-\tilde{R}^{U C}$.

The reason why the ADV tax revenue is always greater than the unit tax revenue can be explained as follows. In our model, the total expenditure for the differentiated goods has a constant value $\mu .^{8}$ Because all consumers buy the differentiated products in their home country in the closed economy, the total revenue of the firms is constant regardless of the tax rate. The revenue-maximizing government, therefore, sets its tax rate as high as possible. When the government uses the ADV tax method, it sets the tax rate as $r_{i}=1$ to reap all firm revenue, which yields a government revenue of $\mu$. In contrast, when the government uses the unit tax and chooses an indefinitely high tax rate, it cannot reap all firm revenue, because the firms keep the market power, represented by the reciprocal of $\sigma$ in (15). As a result, the government collects revenue less than $\mu$.

\subsection{Short-run analysis with cross-border shopping}

Unit tax competition by both governments. In the short run, the number of firms is fixed such that $d n_{j} / d t_{j}=0$ and $n_{i}=n_{j}$ in the symmetric equilibrium. Then, the maximization of tax revenue when two governments compete in unit tax gives

$$
\begin{aligned}
\frac{d R_{j}^{U}}{d t_{j}} & =\frac{\mu(\sigma-1)}{\sigma}\left[\frac{c l_{j}}{\left(c+t_{j}\right)^{2}}+\frac{t_{j}}{c+t_{j}} \frac{d l_{j}}{d t_{j}}\right] \\
& =\frac{\mu(\sigma-1)}{\sigma}\left[\frac{c l_{j}}{\left(c+t_{j}\right)^{2}}+\frac{t_{j}}{c+t_{j}}\left(-\frac{\mu}{2 \tau} \cdot \frac{1}{c+t_{j}}\right)\right]=0,
\end{aligned}
$$

which yields $t_{j}=2 \tau c l_{j} / \mu$. Under a symmetric equilibrium, we have $l_{1}=l_{2}=1$. Thus, the equilibrium unit tax rate of country $j, \hat{t}_{j}$, is obtained as follows. ${ }^{9}$

$$
\hat{t}^{U O}=\hat{t}_{1}=\hat{t}_{2}=\frac{2 \tau c}{\mu},
$$

where superscript $O$ denotes the equilibrium value when consumers cross the open border. Substituting (18) into (6) with $r_{j}=0$, we have $\hat{p}^{U O}=\sigma(2 \tau+\mu) c /(\sigma-1) \mu>c$. The firm sets its price above the marginal cost based on its market power, and the equilibrium price increases as the transportation cost increases; $\partial \hat{p}^{U O} / \partial \tau>0$. In addition, substituting (18) and $l_{j}=1$ into (13), the tax revenue of country $j$ in the short-run equilibrium when two symmetric governments compete in a unit tax, $\hat{R}_{j}^{U}$, is given by

$$
\hat{R}_{j}^{U}\left(\hat{t}_{1}, \hat{t}_{2}\right)=\hat{R}^{U O}=\frac{\sigma-1}{\sigma} \cdot \frac{2 \tau \mu}{2 \tau+\mu} .
$$

$A D V$ tax competition by both governments. When two governments use an ADV tax, the first-order condition for revenue-maximization is given by

\footnotetext{
${ }^{8}$ Substituting $H$ in (3) into (2), we obtain $\int_{0}^{n_{j}} p_{j}(i) m_{j}(i) d i=\mu$.

${ }^{9}$ Because the two reaction curves derived from (17) for $i=1,2$ are symmetric with respect to a 45 -degree $\left(t_{1}=t_{2}\right)$ line, there is a unique symmetric equilibrium. The same is true for the ADV tax rate presented in (20).
} 


$$
\frac{d R_{j}^{A}}{d r_{j}}=\mu\left[l_{j}+r_{j} \frac{d l_{j}}{d r_{j}}\right]=\mu\left[l_{j}+r_{j}\left(-\frac{\mu}{2 \tau} \cdot \frac{1}{1-r_{j}}\right)\right]=0,
$$

which yields the ADV tax rate as $r_{j}=2 \tau l_{j} /\left(2 \tau l_{j}+\mu\right)$. With $l_{1}=l_{2}=1$, the equilibrium tax rate of country $j$ when two governments use an $\mathrm{ADV}$ tax rate is given by

$$
\hat{r}^{A O}=\hat{r}_{1}=\hat{r}_{2}=\frac{2 \tau}{2 \tau+\mu} .
$$

Using (6), (20), and $t_{j}=0$, we obtain $\hat{p}^{A O}=\hat{p}^{U O}$, which shows that the price under the ADV tax competition is identical to that under the unit tax competition. Furthermore, from (14) and $l_{j}=1$ with (20), we obtain the tax revenue of country $j$ in the short-run symmetric equilibrium when the two governments compete in the ADV tax method, $\hat{R}_{j}^{A}$, as

$$
\hat{R}_{j}^{A}\left(\hat{r}_{1}, \hat{r}_{2}\right)=\hat{R}^{A O}=\frac{2 \tau \mu}{2 \tau+\mu}
$$

Comparing (19) with (21), we have

$$
\hat{R}^{A O}-\hat{R}^{U O}=\frac{2 \tau \mu}{\sigma(2 \tau+\mu)}>0
$$

which leads to the following result.

Lemma 1. The ADV tax revenue is greater than the unit tax revenue when the transport cost is sufficiently low to ensure cross-border shopping in the short-run equilibrium; $\hat{R}^{A O}>\hat{R}^{U O}$.

This result shows that the superiority of the ADV tax still holds even if the border is opened such that the governments compete for mobile consumers. The reason is as follows. The competition for mobile consumers caused by the border openings forces the government to lower its tax rate, which contributes to lowering the equilibrium price. This mechanism applies both in the unit tax and ADV tax competition. In addition, as in the standard argument with no cross-border shopping, the ADV tax method can weaken the market power of firms and achieves lower prices compared with the unit tax method if the same tax revenue is obtained from a unit and an ADV tax. Conversely, the revenue from a given ADV tax is always larger than that from the unit tax, which results in the same equilibrium price. This can be confirmed in our model as follows. Given that $\hat{p}^{A O}=\hat{p}^{U O}$, we can compare the effective tax rate between the unit tax and the ADV tax by making an equivalent conversion between two tax methods, $t^{A O}=r^{A O} p^{O}$, where $t^{A O}$ represents the tax rate converted to the tax per unit of goods under the ADV tax. ${ }^{10}$ Substituting (20) and $\hat{p}^{U O}\left(=\hat{p}^{A O}\right)$ into $t^{A O}=r^{A O} p^{O}$, we have $\hat{t}^{A O}=2 \tau \sigma c /(\sigma-1)$, which is higher than $\hat{t}^{U O}=2 \tau c / \mu{ }^{11}$ Because the government can impose a higher tax per unit consumption under the ADV tax competition, it collects higher tax revenue in the symmetric equilibrium.

\footnotetext{
${ }^{10}$ See, for instance, Suits and Musgrave (1953, p.601), Salanié (2002, p.21), and Aiura and Ogawa (2014). ${ }^{11} \hat{t}^{A O}-\hat{t}^{U O}=2 \tau c[\sigma(\mu-1)+1] / \mu(\sigma-1)>0$.
} 


\subsection{Long-run analysis with cross-border shopping}

Unit tax competition by both governments. In the long run, changes in the tax rate impact the number of firms. Using (8) and (9), we have ${ }^{12}$

$$
\frac{d n_{j}}{d t_{j}}=-\frac{\mu(\sigma-1) n_{j}}{\left[2 \tau(\sigma-1) l_{j}-\mu\right]\left(c+t_{j}\right)} .
$$

Using (23), the first-order condition for revenue maximization in the long run is given by

$$
\begin{aligned}
\frac{d R_{j}^{U}}{d t_{j}} & =\frac{\mu(\sigma-1)}{\sigma}\left[\frac{c l_{j}}{\left(c+t_{j}\right)^{2}}+\frac{t_{j}}{c+t_{j}}\left(\frac{d l_{j}}{d t_{j}}+\frac{d l_{j}}{d n_{j}} \frac{d n_{j}}{d t_{j}}\right)\right] \\
& =\frac{\mu(\sigma-1)}{\sigma} \frac{\left[2 \tau(\sigma-1) l_{j}-\mu\right] c l_{j}-\mu(\sigma-1) l_{j} t_{j}}{\left[2 \tau(\sigma-1) l_{j}-\mu\right]\left(c+t_{j}\right)^{2}}=0,
\end{aligned}
$$

which yields

$$
t_{j}=\frac{\left[2 \tau(\sigma-1) l_{j}-\mu\right] c}{(\sigma-1) \mu}
$$

Using $l_{j}=1$ in the symmetric equilibrium, we have the tax rate of country $j$ in the long-run equilibrium when the two governments compete in a unit tax, $\tilde{t_{j}}$, as follows: ${ }^{13}$

$$
\tilde{t}^{U O}=\tilde{t}_{1}=\tilde{t}_{2}=\frac{[2 \tau(\sigma-1)-\mu] c}{(\sigma-1) \mu}
$$

To analyze the tax effects in the stable and relevant equilibrium, we make the following assumption.

Assumption 1 (Stability Condition). $2 \tau(\sigma-1)-\mu>0$.

Assumption 1 ensures the stability of the long-run symmetric equilibrium and determines the sign of (23) and $(25) .^{14}$

Using (6) and (25) with $r_{j}=0$, we have $\tilde{p}^{U O}=\sigma[(\sigma-1)(2 \tau+\mu)-\mu] c / \mu(\sigma-1)^{2}$. In addition, from (9) with $r_{j}=0$ and $l_{j}=1$, we have $\tilde{n}^{U O}=\mu / \sigma f$ in the symmetric equilibrium. From the comparison of shortrun and long-run equilibrium, we find that $\hat{t}^{U O}-\tilde{t}^{U O}=c /(\sigma-1)>0$ and $\hat{p}^{U O}-\tilde{p}^{U O}=c \sigma /(\sigma-1)^{2}>0$, indicating that the presence of a firm's entry leads to lower tax and lower prices. Finally, substituting (25) and $l_{j}=1$ into (13), we obtain the tax revenue of country $j$ in the long-run equilibrium when the two governments use a unit tax, $\tilde{R}_{j}^{U}$, as

$$
\tilde{R}_{j}^{U}\left(\tilde{t}_{1}, \tilde{t}_{2}\right)=\tilde{R}^{U O}=\frac{\sigma-1}{\sigma} \frac{2 \tau(\sigma-1)-\mu}{(2 \tau+\mu)(\sigma-1)-\mu} \mu .
$$

\footnotetext{
${ }^{12}$ See Appendix A.

${ }^{13}$ Because the two reaction curves derived from $(24)$, for $i=1,2$, are symmetric with respect to a 45 degree $\left(t_{1}=t_{2}\right)$ line, there is a unique symmetric equilibrium. The same is true for the case of ADV tax competition presented by (28).

${ }^{14}$ See Appendix B.
} 
ADV tax competition by both governments. The governments account for the tax effects on the number of firms in the long-run equilibrium. When the two governments compete in an ADV tax, using (8) and (9), the effect of a change in the ADV tax rate on the number of firms can be obtained as follows. ${ }^{15}$

$$
\frac{d n_{j}}{d r_{j}}=-\frac{\left(2 \tau l_{j}+\mu\right)(\sigma-1) n_{j}}{\left[2 \tau(\sigma-1) l_{j}-\mu\right]\left(1-r_{j}\right)}
$$

Using (27), the revenue-maximization problem gives the first-order condition as

$$
\begin{aligned}
\frac{d R_{j}^{A}}{d r_{j}} & =\mu\left[l_{j}+r_{j}\left(\frac{d l_{j}}{d r_{j}}+\frac{d l_{j}}{d n_{j}} \frac{d n_{j}}{d r_{j}}\right)\right] \\
& =\mu l_{j}\left(1-\frac{\mu \sigma}{2 \tau(\sigma-1) l_{j}-\mu} \frac{r_{j}}{1-r_{j}}\right)=0
\end{aligned}
$$

which yields

$$
r_{j}=\frac{2 \tau(\sigma-1) l_{j}-\mu}{(\sigma-1)\left(2 \tau l_{j}+\mu\right)} .
$$

Substituting the symmetric equilibrium condition, $l_{j}=1$, we obtain the ADV tax rate of country $j$ in the long run, $\tilde{r}_{j}$, as

$$
\tilde{r}^{A O}=\tilde{r}_{1}=\tilde{r}_{2}=\frac{2(\sigma-1) \tau-\mu}{(\sigma-1)(2 \tau+\mu)}
$$

which can be used with $l_{j}=1$ and (14) to obtain the tax revenue of country $j$ in the long run when the two governments compete in an $\mathrm{ADV}$ tax, $\tilde{R}_{j}^{A}$ :

$$
\tilde{R}_{j}^{A}\left(\tilde{r}_{1}, \tilde{r}_{2}\right)=\tilde{R}^{A O}=\frac{2(\sigma-1) \tau-\mu}{(\sigma-1)(2 \tau+\mu)} \mu .
$$

From the comparison of equilibrium values between short-run and long-run outcomes, we again find that the presence of a firm's entry reduces the ADV tax rate and price level in the market; $\hat{r}^{A O}>\tilde{r}^{A O}$ and $\hat{p}^{A O}>\tilde{p}^{A O}$.

The equilibrium comparison between the unit tax and ADV tax method reveals the following properties. First, using (6) and (28) with $t_{j}=0$, we obtain $\tilde{p}^{A O}=(2 \tau+\mu) c / \mu<\tilde{p}^{U O}$, which shows that the ADV tax is superior to the unit tax method in reducing the equilibrium price of differentiated products. ${ }^{16}$ Second, from (9), (28), and $l_{j}=1$, the number of firms in the symmetric equilibrium is given by $\tilde{n}^{A O}=\mu^{2} /(\sigma-1)(2 \tau+\mu) f<\tilde{n}^{U O}$, which shows that the number of firms in the ADV tax competition is smaller than that under the unit tax competition. ${ }^{17}$ This is because the ADV tax method reaps more revenue of firms than the unit tax does and because it is more difficult for firms to survive. Finally, a comparison of (26) and (29) shows that

\footnotetext{
${ }^{15}$ See Appendix C.

${ }^{16} \tilde{p}^{U O}-\tilde{p}^{A O}=[2 \tau(\sigma-1)-\mu] / \mu(\sigma-1)^{2}>0$. The inequality arises from Assumption 1.

${ }^{17} \tilde{n}^{U O}-\tilde{n}^{A O}=\mu[2 \tau(\sigma-1)-\mu] / \sigma(\sigma-1)(2 \tau+\mu) f>0$. The inequality comes from Assumption 1.
} 


$$
\tilde{R}^{A O}-\tilde{R}^{U O}=\frac{[2(\sigma-1) \tau-\mu]^{2}}{\sigma(\sigma-1)(2 \tau+\mu)[(\sigma-1)(2 \tau+\mu)-\mu]} \mu>0,
$$

which yields the following result.

Lemma 2. The ADV tax revenue is greater than the unit tax revenue when the transport cost is sufficiently low to ensure cross-border shopping in the long-run equilibrium, $\tilde{R}^{A O}>\tilde{R}^{U O}$.

This result suggests that an ADV tax is tax-revenue superior to a unit tax not only in the short run but also in the long run. However, an ADV tax method loses its advantage to some extent in the long run:

$$
\begin{aligned}
\tilde{R}^{A O}-\tilde{R}^{U O} & =\frac{\mu}{\sigma} \frac{[2(\sigma-1) \tau-\mu]^{2}}{(\sigma-1)(2 \tau+\mu)[(\sigma-1)(2 \tau+\mu)-\mu]} \\
& <\frac{\mu}{\sigma}\left(\frac{2 \tau}{2 \tau+\mu}\right)^{2}<\frac{2 \tau}{2 \tau+\mu}=\hat{R}^{A O}-\hat{R}^{U O} .
\end{aligned}
$$

This result is summarized as follows.

Proposition 2. The tax-revenue gap between an $A D V$ tax and a unit tax in the long run is smaller than that in the short run: $0<\tilde{R}^{A O}-\tilde{R}^{U O}<\hat{R}^{A O}-\hat{R}^{U O}$.

This result can be explained by focusing on the governments' incentive to increase the number of firms in the long run. In the symmetric equilibrium, the number of firms under an ADV tax is smaller than that under a unit tax: $\tilde{n}^{A O}<\tilde{n}^{U O}$. Therefore, compared with the unit tax case, the government with an ADV tax has a stronger incentive to increase the number of firms by cutting its tax rate. In this case, the government reduces its tax rate more aggressively than it does under the unit tax competition. In contrast, in the short run, the government does not have incentives to reduce the ADV tax rate because the number of firms is exogenously fixed. This induces the government to choose a higher ADV tax rate in the short run than it does in the long run. Therefore, the ADV tax revenue in the long run becomes smaller than the short-run ADV tax revenue, which narrows the tax-revenue gap between the ADV tax and unit tax in the long run.

\subsection{Impacts of Border Openings}

The previous sections showed that in the long run, the entry of firms narrows the tax-revenue gap between the ADV tax and the unit tax. Here, we study the impact of an open border on the tax-revenue gap by comparing the tax revenue in a closed-border economy to that in an open-border economy.

As shown in Lemmas 1 and 2, the superiority of the ADV tax prevails in both the short and long run. However, cross-border shopping caused by the opening of the border closes the tax-revenue gap between the ADV tax and the unit tax. This can be confirmed using (15), (16), (22), and (30) to obtain

$$
\hat{R}^{A C}-\hat{R}^{U C}>\hat{R}^{A O}-\hat{R}^{U O} \text { and } \tilde{R}^{A C}-\tilde{R}^{U C}>\tilde{R}^{A O}-\tilde{R}^{U O},
$$

which leads to the following result. 
Proposition 3. Once consumers can cross the border, the tax-revenue gap between the ADV tax competition and the unit tax competition decreases in the short and long run.

Proof. See Appendix D.

As explained, when consumers cross the border, the government has a further incentive to reduce its ADV tax rate to invite mobile consumers. However, in a symmetric equilibrium, all governments reduce their tax rate in a similar manner. Thus, there is no net inflow of consumers linked to the lower tax rate. This leads to a reduction in ADV tax revenue, which narrows the revenue gap between the ADV tax and the unit tax in the presence of cross-border shopping.

\section{Welfare-maximizing Government}

Thus far, we have assumed that each country maximizes its revenue, which can be partly justified by assuming a Leviathan-type government. As an alternative government objective, we extend the model by assuming a benevolent government that maximizes domestic welfare, which consists of consumers' utility, firms' profit, and tax revenue. For example, the domestic welfare in country 1 is given by

$$
W_{1}= \begin{cases}\int_{-1}^{0} U_{1}(x) d x+n_{1} \pi_{1}+R_{1} & \text { if } l_{1} \geq 1, \\ \int_{-1}^{-1+l_{1}} U_{1}(x) d x+\int_{-1+l_{1}}^{0} U_{2}(x) d x+n_{1} \pi_{1}+R_{1} & \text { if } l_{1}<1 .\end{cases}
$$

which can be rewritten as

$$
\begin{array}{rlr}
W_{1}^{+}= & I-\mu+\mu \ln M_{1}-\int_{-1}^{0} F_{1}(x) d x+n_{1} \pi_{1}+R_{1} & \text { if } l_{1} \geq 1, \\
W_{1}^{-}= & I-\mu+l_{1} \mu \ln M_{1}-\int_{-1}^{-1+l_{1}} F_{1}(x) d x & \\
& +\left(1-l_{1}\right) \mu \ln M_{2}-\int_{-1+l_{1}}^{0} F_{2}(x) d x+n_{1} \pi_{1}+R_{1} \quad \text { if } l_{1}<1 .
\end{array}
$$

From (1), (3), and (6), we have

$$
M_{j}=\frac{\mu(\sigma-1)\left(1-r_{j}\right)}{\sigma\left(c+t_{j}\right)} n_{j}^{\frac{1}{\sigma-1}} .
$$

Recall that $l_{1}=1$ and $M_{1}=M_{2}$ hold in the symmetric equilibrium. Therefore, we have

$$
\left.\frac{d W_{1}^{+}}{d t_{1}}\right|_{l_{1}=1}=\left.\frac{d W_{1}^{-}}{d t_{1}}\right|_{l_{1}=1 \text { and } M_{1}=M_{2}} \text { and }\left.\quad \frac{d W_{1}^{+}}{d r_{1}}\right|_{l_{1}=1}=\left.\frac{d W_{1}^{-}}{d r_{1}}\right|_{l_{1}=1 \text { and } M_{1}=M_{2}} .
$$

Based on this feature, we derive the equilibrium tax/subsidy rate as in the following subsections. Before studying the short-run and long-run equilibria, the next subsection describes the outcome in the benchmark case in which there is no cross-border shopping.

\subsection{Benchmark: Closed-border economy}

Assume that consumers do not cross the border. In the short-run symmetric equilibrium, there is no difference in the fixed number of firms. Hence, using $n_{i}=n_{j}, d l_{j} / d t_{j}=0$ and $d n_{j} / d t_{j}=0$ and evaluating 
at the symmetric equilibrium $\left(l_{j}=1\right)$, the maximization of domestic welfare with respect to the unit tax rate yields

$$
\left.\frac{d W_{j}^{+}}{d t_{j}}\right|_{l_{j}=1}=-\frac{\sigma t_{j}+c}{\sigma\left(c+t_{j}\right)^{2}} \mu=0 .
$$

Solving this equation, the unit tax rate in the short-run symmetric equilibrium, $\hat{t}_{j}$, is given by

$$
\hat{t}^{U C}=\hat{t_{1}}=\hat{t_{2}}=-\frac{c}{\sigma}<0
$$

In a similar manner, when the government uses an ADV tax, using $d l_{j} / d r_{j}=0$ and $d n_{j} / d r_{j}=0$ and evaluating at the symmetric equilibrium, the maximization problem is

$$
\left.\frac{d W_{j}^{+}}{d r_{j}}\right|_{l_{j}=1}=-\frac{(\sigma-1) r_{j}+1}{\sigma\left(1-r_{j}\right)} \mu=0 .
$$

Hence, the equilibrium ADV tax rate in the short-run symmetric equilibrium, $\hat{r}_{j}$, is

$$
\hat{r}^{A C}=\hat{r}_{1}=\hat{r}_{2}=-\frac{1}{\sigma-1}<0 .
$$

Using (31) and (32) with (6), we find that $\hat{p}^{A C}=\hat{p}^{U C}=c$. Here, (31) and (32) show that the government provides a subsidy to firms in the monopolistic competition market. The reason is simple. By providing subsidies to firms, the government induces them to produce more because the imperfectly competitive firms produce less output and set their price above the marginal cost. That is, the government induces firms to follow marginal cost pricing.

The long-run equilibrium in the benchmark case can be derived in a similar manner. Using $d l_{j} / d t_{j}=0$ and $d n_{j} / d t_{j}=0$ with $\pi_{j}=0$ and maximizing welfare with respect to the unit tax rate, the unit tax rate in the long run is given as $\tilde{t}^{U C}=\hat{t}^{U C}$. In turn, when the government maximizes domestic welfare with respect to the ADV tax rate using $d l_{j} / d r_{j}=0$ and $d n_{j} / d r_{j}=-\mu l_{j} /(\sigma f)$, with $\pi_{j}=0$, the maximization problem becomes

$$
\left.\frac{d W_{j}^{+}}{d r_{j}}\right|_{l_{j}=1}=-\frac{(\sigma-1) r_{j}+1}{(\sigma-1)\left(1-r_{j}\right)} \mu=0 .
$$

This provides the equilibrium ADV tax rate in the long run as $\tilde{r}^{A C}=\hat{r}^{A C}$.

Using the equilibrium tax rates, we easily find that the firms choose their prices as $\tilde{p}^{A C}=\tilde{p}^{U C}=c$. In this case, the number of firms under ADV tax and the unit tax is given, respectively, as $\tilde{n}^{A C}=\mu /(\sigma-1) f$ and $\tilde{n}^{U C}=\mu / \sigma f$, showing that the number of firms under ADV tax is larger than that under the unit tax. This contrasts the case of the revenue-maximizing government in which the number of firms under the ADV tax is smaller than that under the unit tax. This is because the ADV subsidy tax method increases the firms' revenue more than the unit subsidy does and because firms can survive more easily under the AVD subsidy tax method.

Using the equilibrium tax rates, we obtain the maximum welfare in the case of a unit tax and an ADV tax in the short and long run. Comparing the maximum welfare values leads to the following result. 
Proposition 4. When consumers do not cross the border, (i) there is no welfare gap between an ADV tax and unit tax in the short run, but the welfare under the ADV tax is greater than that under the unit tax in the long run; $\hat{W}^{U C}=\hat{W}^{A C}$ and $\tilde{W}^{A C}>\tilde{W}^{U C}$, and thus, (ii) the welfare gap between the ADV tax and unit tax in the long run is greater than in the short run.

Proof. See Appendix E.

In the long run, we confirm that an $\mathrm{ADV}$ tax is superior to the unit tax not only from the tax-revenue standard shown in Lemmas 1 and 2 but also from the aspect of welfare. However, in the short run, the ADV tax and unit tax are equivalent in terms of welfare, which contrasts with the case of tax-revenue maximization in which the ADV tax is superior to the unit tax (see Proposition 1). The reason why there is no difference in welfare between the unit tax and the ADV tax in the short run can be explained as follows.

Welfare is maximized in the closed-border economy if the marginal utility of services, $\mu /\left(n_{j} m_{j}\right)$, is equal to the marginal cost of service production, $c$, such that the tax rate is determined to satisfy $\mu /\left(n_{j} m_{j}\right)=c$. Hence, the total consumption of differentiated products, $n_{j} m_{j}$, is on par regardless of the tax system. Thus, the welfare under the two tax methods in which the number of firms in the two regions is identical becomes the same in the short run. In contrast, the number of firms is determined endogenously in the long run. Because we make a love-of-variety assumption in (1), the utility increases as the number of firms in the region increases. Thus, welfare under the ADV tax is greater than that under the unit tax owing to the greater number of firms when using an ADV tax.

\subsection{Short-run equilibrium with cross-border shopping}

In this section, we derive the unit tax rate in the short-run equilibrium when consumers cross the border. Because the number of firms is still fixed and identical between the two regions, using $d n_{j} / d t_{j}=0$ and $n_{i}=n_{j}$, the maximization of domestic welfare with respect to the unit tax rate yields

$$
\left.\frac{d W_{j}^{+}}{d t_{j}}\right|_{l_{j}=1}=-\frac{(2 \tau+\mu)\left(\sigma t_{j}+c\right)}{2 \tau \sigma\left(c+t_{j}\right)^{2}} \mu=0 .
$$

Solving this equation, we have the unit tax rate which is identical to that given by $(31), \hat{t}^{U O}=\hat{t}^{U C}$. Substituting the tax rate into (6) with $r_{j}=0$, we have $\hat{p}^{U O}=c$, implying that the government sets its tax rate to make firms follow marginal-cost pricing. When the government uses an ADV tax, evaluating $d n_{j} / d r_{j}=0$ at the symmetric equilibrium $\left(l_{j}=1\right)$, the tax rate in the short-run equilibrium when consumers cross the border is as follows:

$$
\left.\frac{d W_{j}^{+}}{d r_{j}}\right|_{l_{j}=1}=-\frac{(2 \tau+\mu)\left[(\sigma-1) r_{j}+1\right]}{2 \tau \sigma\left(1-r_{j}\right)} \mu=0 .
$$

This gives the equilibrium ADV tax rate, which is identical to that given by (32), $\hat{r}^{A O}=\hat{r}^{A C}$. Using the equilibrium tax rate and (6), we have $\hat{p}^{A O}=c$. Given that $\hat{W}^{A C}=\hat{W}^{U C}$ and $\hat{r}^{A O}=\hat{r}^{A C}$, we 
immediately have the following result.

Lemma 3. In the short run, the domestic welfare with the unit tax method is equivalent to that with the ADV tax method and is independent of consumers' mobility: $\hat{W}^{A C}=\hat{W}^{U C}=\hat{W}^{A O}=\hat{W}^{U O}$.

Proof. See Appendix F.

Lemmas 1 and 2 show the superiority of the ADV tax in terms of tax revenue. However, Lemma 3 indicates that no difference exists in welfare between the tax methods in the short run in which the number of firms is assumed to be fixed. The intuitive explanation behind this result is given later with Lemma 4.

\subsection{Long-run equilibrium with cross-border shopping}

In this section, we derive the unit tax rate in the long-run equilibrium when consumers cross the border. The tax effects on the number of firms in each country are given by (23). In addition, in the long-run equilibrium, $\pi_{j}=0$ holds. Using these equations, in the symmetric equilibrium, we have

$$
\left.\frac{d W_{j}^{+}}{d t_{j}}\right|_{l_{j}=1}=-\frac{[2 \tau \sigma+\mu(\sigma-1)] t_{j}+(2 \tau+\mu) c}{\sigma[2 \tau(\sigma-1)-\mu]\left(c+t_{j}\right)^{2}}(\sigma-1) \mu=0 .
$$

Solving this equation, the unit tax rate in the long-run equilibrium with consumer mobility, $\tilde{t}_{j}$, is obtained as

$$
\tilde{t}^{U O} \equiv \tilde{t}_{1}=\tilde{t}_{2}=-\frac{2 \tau+\mu}{2 \tau \sigma+\mu(\sigma-1)} c<0 .
$$

Using (31) and (33), a comparison of unit subsidy rates reveals that the government chooses a higher unit subsidy rate in the long run than in the short run when consumers are able to cross the border, $\left|\tilde{t}^{U O}\right|>\left|\hat{t}^{U O}\right|$. This is because in addition to the government incentive to respond to underproduction caused by imperfect competition, the governments have an incentive to encourage firms to enter the market to attract consumers from abroad, which leads the government to provide more subsidies to firms in the long run. This feature differentiates the equilibrium price in the long-run unit tax competition with other cases. Under the ADV tax competition, the governments choose the tax rate to make firms set their price according to the marginal-cost pricing rule in both the short and long-run. ${ }^{18}$ This minimizes the welfare loss from imperfect competition. In the long-run unit tax competition, however, the government provides a subsidy to make firms set their prices below the marginal cost, and the additional firm deficits are made up by the government. This can be easily confirmed by the substitution of (33) and $r_{i}=0$ into (6) to obtain

$$
\tilde{p}^{U O}=\frac{\sigma}{\sigma-1}\left(1-\frac{2 \tau+\mu}{2 \tau \sigma+\mu(\sigma-1)}\right) c=\frac{\sigma[(\sigma-1)(2 \tau+\mu)-\mu]}{\sigma[(\sigma-1)(2 \tau+\mu)-\mu]+\mu}<c .
$$

\footnotetext{
${ }^{18}$ For example, in the short-run equilibrium case, substituting (32) and $t_{i}=0$ into (6) provides the equilibrium price in the ADV tax competition as $\hat{p}^{A C}=c$.
} 
Because the consumers benefit from variety, the welfare-maximizing government has incentives to increase the number of firms in the country. In the symmetric equilibrium, $l_{i}=1$, from (9) with $r_{i}<0$, we find that the number of firms under the unit tax competition is smaller than that under the ADV tax competition, $\tilde{n}^{U O}<\tilde{n}^{A O}$, suggesting that the government with a unit tax method has a stronger incentive to increase the number of firms compared with the government using the ADV tax. Consequently, the government under the unit method provides a more aggressive subsidy to increase the product variety while it chooses its subsidy rate to create welfare loss from taxation under the ADV method.

Now, consider the case in which the government uses an ADV tax in the presence of cross-border shopping. In the long run, $\pi_{j}=0$ holds. In addition, the ADV tax effect on the number of firms is given by (27). Using these equations and $\pi_{j}=0$, we obtain

$$
\left.\frac{d W_{j}^{+}}{d r_{j}}\right|_{l_{j}=1}=-\frac{(2 \tau+\mu)\left[(\sigma-1) r_{j}+1\right]}{[2 \tau(\sigma-1)-\mu]\left(1-r_{j}\right)} \mu=0 .
$$

Therefore, the ADV tax rate is identical to that given by $(32), \tilde{t}^{A O}=\hat{t}^{A O}$, which results in $\tilde{p}^{A O}=c$.

The substitution of tax rates in the government objective function gives the domestic welfare in the long run, and comparing welfare under the different tax methods yields the following result.

Lemma 4. Welfare under the $A D V$ tax is greater than that under the unit tax when the transport cost is sufficiently low to ensure cross-border shopping in the long-run equilibrium, $\tilde{W}^{A O}>\tilde{W}^{U O}$.

Proof. Because the presence of cross-border shopping induces governments to reduce the unit tax rates, the welfare in the symmetric long-run equilibrium with cross-border shopping under the unit tax method, $\tilde{W}^{U O}$, is always smaller than the long-run welfare without cross-border shopping, $\tilde{W}^{U C}$ : $\tilde{W}^{U O}<\tilde{W}^{U C}$. In the long run, because the ADV tax rate with cross-border shopping is identical to that in the absence of cross-border shopping, we have $\tilde{W}^{A C}=\tilde{W}^{A O}$. Hence, from $\tilde{W}^{U C}<\tilde{W}^{A C}$, we have $\tilde{W}^{U O}<\tilde{W}^{A O}$.

The number of firm is fixed in the short-run equilibrium. Thus, it is impossible for governments to increase domestic welfare by increasing the number of firms. However, they can increase welfare by changing the price through their choice of tax method. This argument applies not only to the economy with cross-border shopping but also to a closed economy. Hence, the tax rates chosen by the government are the same in an open and closed economy. In addition, the resulting welfare level is identical regardless of the tax method chosen in the short run, which explains Lemma 3.

In the long run without cross-border shopping, the number of firms is now endogenously determined. Thus, the government has incentives to increase the variety in its country by choosing the tax rate and method. As shown in this section, when the government maximizes domestic welfare, it chooses a negative tax rate. This means that the number of firms under the unit tax method is smaller than that under the ADV tax method. In this case, the government using a unit tax has stronger incentives to increase the number of firms and thereby provides a subsidy more aggressively compared with the government with 
the ADV tax. All countries support massive subsidies, but they all fail to increase the number of firms in the symmetric equilibrium, which results in lower domestic welfare. Conversely, the larger number of firms under the ADV tax method results in higher domestic welfare in equilibrium, which explains Lemma 4 .

Finally, comparing domestic welfare between the short run and long run provides the following result.

Proposition 5. The welfare gap between an $A D V$ tax and unit tax in the long run is larger than that in the short run: $\tilde{W}^{A O}-\tilde{W}^{U O}>\hat{W}^{A O}-\hat{W}^{U O}$.

Proof. From Lemmas 3 and 4 , we have $\hat{W}^{A O}=\hat{W}^{U O}$ and $\tilde{W}^{A O}>\tilde{W}^{U O}$. Hence, $\tilde{W}^{A O}-\tilde{W}^{U O}>$ $\hat{W}^{A O}-\hat{W}^{U O}=0$.

This result suggests that the entry of firms strengthens the welfare superiority of the ADV tax method.

\subsection{Impacts of Border Openings}

Finally, we compare the welfare between a unit tax and an ADV tax with and without cross-border shopping. Here, we have the following result.

Proposition 6. Once the consumers cross the border, the welfare gap between ADV tax competition and unit tax competition is unchanged in the short run: $\hat{W}^{A C}-\hat{W}^{U C}=0=\hat{W}^{A O}-\hat{W}^{U O}$. However, cross-border shopping increases the welfare gap between the ADV tax competition and unit tax competition in the long run: $0<\tilde{W}^{A C}-\tilde{W}^{U C}<\tilde{W}^{A O}-\tilde{W}^{U O}$.

Proof. Lemma 3 proves the first part of Proposition 6. From Proposition 4 and Lemma 4, we have $\tilde{W}^{A C}>\tilde{W}^{U C}$ and $\tilde{W}^{A O}>\tilde{W}^{U C}$. Because $\tilde{W}^{A C}=\tilde{W}^{A O}$ and $\tilde{W}^{U O}<\tilde{W}^{U C}$ (see the proof of Proposition 4), we have $0<\tilde{W}^{A C}-\tilde{W}^{U C}<\tilde{W}^{A O}-\tilde{W}^{U O}$.

Once consumers are able to cross the border to shop, the government may benefit from market expansion by attracting consumers from abroad because this increases the profits of domestic firms. However, the increase in firms' profits induced by market expansion is offset by the increase in any form of subsidies used to attract foreign consumers. Hence, the governments have no incentive to change the subsidy rate when the border opens, and the welfare gap between the two tax methods remains unchanged. However, in the long run, there is an additional factor that induces governments to attract consumers from abroad. The government has stronger incentive to increase the number of firms when it uses the unit tax method. Hence, the government with a unit tax reduces its tax rate more aggressively than the government with an ADV tax does. However, the two governments behave in a similar manner, the government fails to increase the variety in the region, and the number of firms remains the same as in the case of the short-run equilibrium. The aggressive unit subsidy competition reduces the equilibrium price below marginal cost, which produces a welfare loss; thus, welfare under the unit tax becomes smaller than that under the ADV tax. 


\section{Discussion}

In sections 3 and 4 , to obtain clear analytical results, we focus on two cases: revenue-maximizing and welfare-maximizing governments. However, both cases seem rather extreme. In this section, a more general formulation is assumed rather than the separate analyses of the revenue-maximizing and welfaremaximizing cases.

Here, the objective function of the government is defined as

$$
V_{i}=\theta R_{i}+(1-\theta) W_{i},
$$

where $\theta \in[0,1]$ is the government weight placed on the tax revenue. When the fiscal revenue is so important for the government that it only cares for tax revenues, $\theta=1$, the analysis reduces to the case of welfare maximization. This case can be justified when governments face severe revenue shortfalls and their tax revenue becomes more important than private good consumption. In contrast, when $\theta=0$, the analysis reduces to that in section 4 , in which the government is allowed to set negative tax rate as shown in section 4 to transfer resources from the consumers to the firms. Reality lies between the two extreme cases, and we reexamine our results using the parameter $\theta$, which suggests the importance of the fiscal revenue constraints the governments face.

Because the method for deriving the results is the same, we simply present the tax rates in the equilibrium to study how they change as $\theta$ changes. ${ }^{19}$ Tables 1 and 2 show the unit tax rate and the ADV tax rate, respectively. In table 2, the equivalent conversion between ADV tax and unit tax is made to compare the effective tax rate between two tax methods; that is, table 2 shows the tax per unit of goods under the ADV tax method.

\begin{tabular}{ccc}
\hline & Short run & Long run \\
\hline Closed border & $\frac{\theta \sigma-1}{(1-\theta) \sigma} c$ & $\frac{\theta \sigma-1}{(1-\theta) \sigma} c$ \\
Open border & $\frac{(2 \tau \sigma+\mu) \theta-(2 \tau+\mu)}{(2 \tau+\mu) \sigma-(2 \tau \sigma+\mu) \theta} c$ & $\frac{2 \tau \sigma \theta-(2 \tau+\mu)}{(2 \tau+\mu) \sigma-\mu-2 \tau \sigma \theta} c$ \\
& & \\
\hline
\end{tabular}

Table 1. Equilibrium unit tax rate

The equilibrium values in tables 1 and 2 can be used to study how they change based on the government's objective changes as weights on the tax revenue, $\theta$. Figures 1 and 2 represent the changes in tax rates and tax revenues, which clearly show that the tax rate and revenue decrease as the government's

\footnotetext{
${ }^{19}$ Details can be obtained from the author upon request.
} 


\begin{tabular}{ccc}
\hline & Short run & Long run \\
\hline Closed border & $\frac{(\sigma+1) \theta-1}{(\sigma-1)(1-\theta)} c$ & $\frac{\theta \sigma-1}{(\sigma-1)(1-\theta)} c$ \\
Open border & $\frac{(2 \tau \sigma+2 \tau+\mu) \theta-(2 \tau+\mu)}{(\sigma-1)[2 \tau(1-\theta)+\mu]} c$ & $\frac{2 \tau \sigma \theta-(2 \tau+\mu)}{(\sigma-1)(2 \tau(1-\theta)+\mu)} c$
\end{tabular}

Table 2. Equilibrium ADV tax

Note. Tax rates are converted to tax per unit of goods under the ADV tax system.

weight on the tax revenue decreases. ${ }^{20}$ They also confirm the argument on the impacts of firm's entry and market openings, which were derived in sections 3 and 4 . For example, figure 1 reveals that the firm's entry in the long-run cuts into both the unit tax and the ADV tax; thus, the tax rates in the long-run equilibrium are not higher than those in the short-run equilibrium for all $\theta \in(0,1]$. In this sense, the unit tax is welfare-superior to the ADV tax in the short run. From figure 1, we also find that the market openings contribute to reducing the tax rates: both the unit and ADV tax rates in the long-run open economy are smaller than those in the long-run closed economy.

The tax rate rankings between the ADV tax and the unit tax are closely related to the tax revenue rankings. It is no wonder that the equilibrium tax revenue increases as the government puts more weight on the tax revenue (see figure 2). In addition, figure 2 easily shows that the firm's entry and market openings act to reduce tax revenues.

Figure 2 also shows that given the same economic environment (i.e., market-openness and the level of firm entry), the slope of the curves under the ADV tax is steeper than that under the unit tax. This implies that the effects on the equilibrium values of a change in the government objective, measured by the marginal change in $\theta$, are larger in the ADV tax competition than those under the unit tax competition. This is because the ADV tax method controls the market power of firms more effectively and because the government with the ADV tax method can have greater effects on the equilibrium values.

Finally, we compare the welfare gap in figure 3 in which $W^{A}-W^{U}$ is measured on the vertical axis. It reveals that in the short run, the welfare under the ADV tax competition is not larger than that under the unit tax competition for $\theta \in[0,1]$. In contrast, in the long run, the ranking is not sufficiently simple: while welfare under the ADV tax competition is still smaller than that under the unit tax competition as long as $\theta$ is high, the ranking is reversed if $\theta$ is sufficiently small. This feature can be explained as follows.

When $\theta$ is large, the government chooses high tax because it puts more weight on revenue. Recall that the ADV tax method can weaken the market power of firms and can collect higher revenues compared

\footnotetext{
${ }^{20}$ For visualization, we set $c=1, \mu=1, \sigma=2, \tau=1$, and $f=1$. The qualitative features do not change if we use other values within a valid set of parameters.
} 


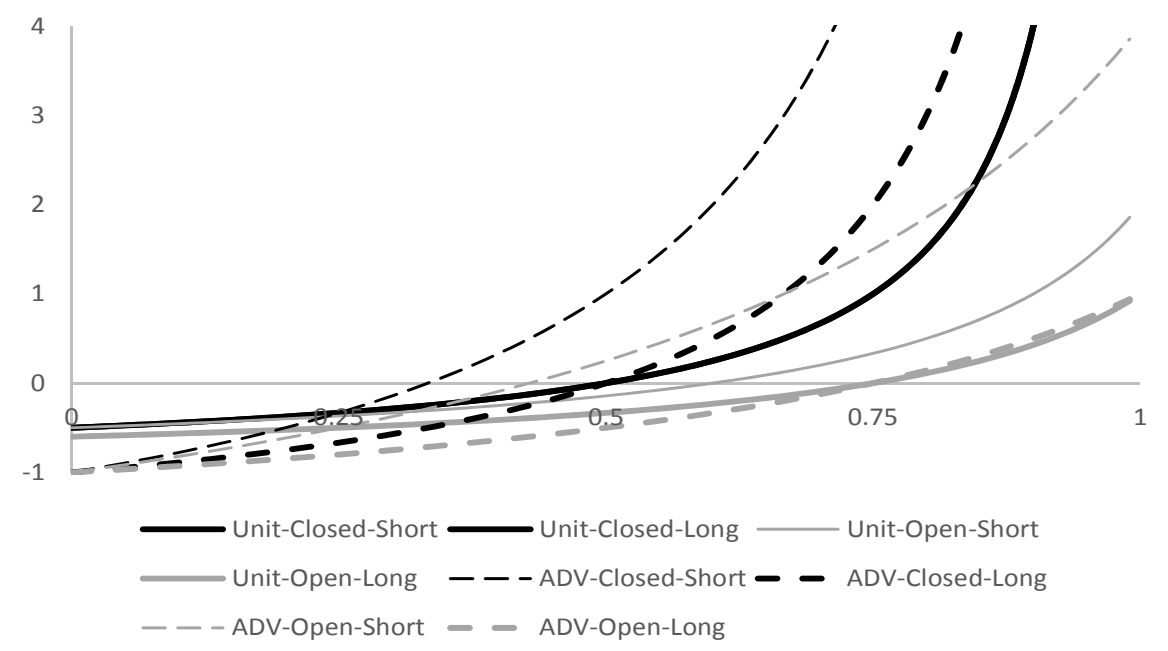

Figure 1: Tax rates

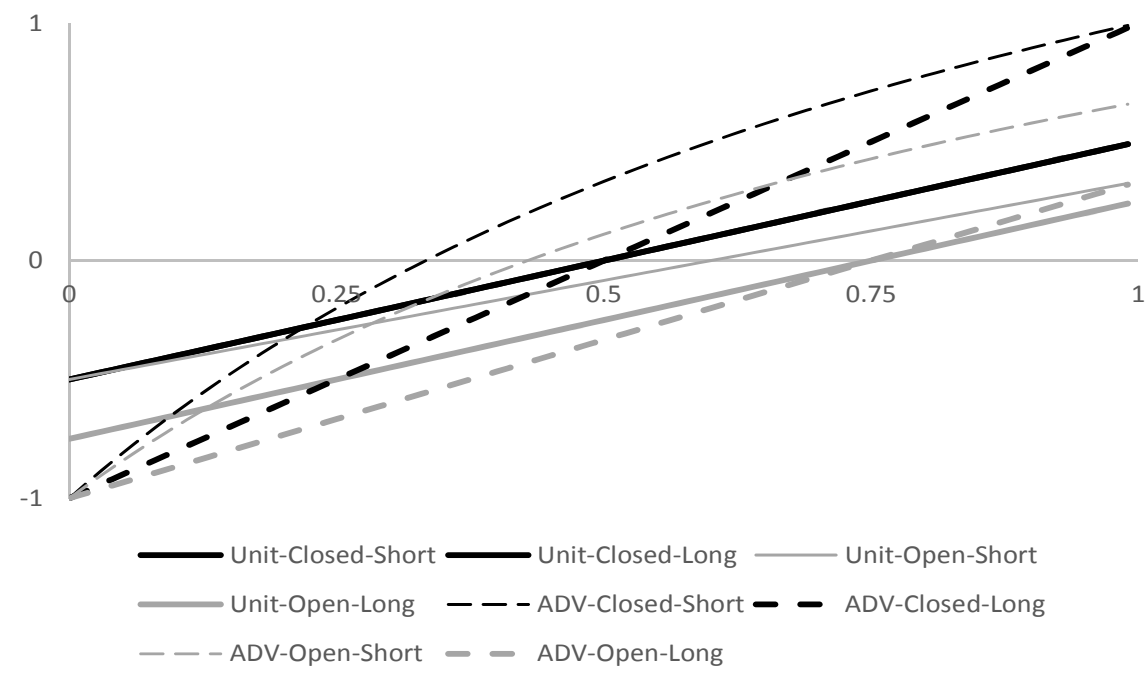

Figure 2: Tax revenue 
with the unit tax. Then, the higher effective tax rate under the ADV method leads to a smaller variety because fewer firms can survive under the high tax rate. Because the consumers benefit from the variety, the welfare under the ADV tax is lower than that under the unit tax.

In contrast, when $\theta$ is sufficiently small where the government puts more weight on welfare, a subsidy is provided to make firms increase the output level and lower the equilibrium price. The subsidy allows firms to survive, and the number of variety increases, benefiting consumers. Compared with the unit method, the government provides a higher subsidy when it uses the ADV method. Hence, the number of firms under the ADV method is larger than that under the unit method, resulting in higher welfare in the ADV subsidy competition than in the unit subsidy competition.

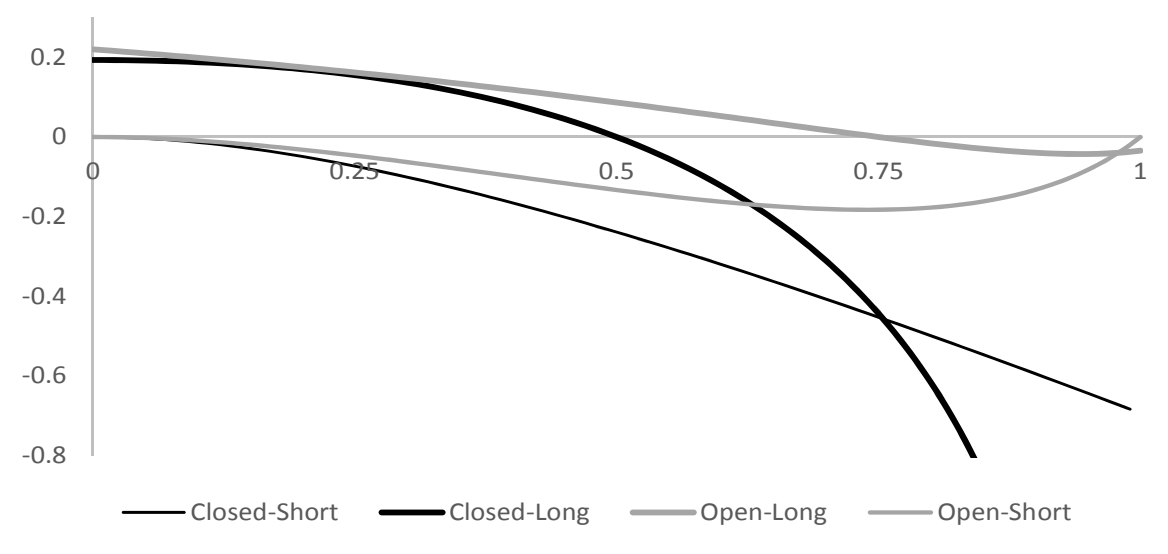

Figure 3: Welfare gap $\left(W^{A}-W^{U}\right)$

\section{Conclusion}

In this study, we examined the efficiency of two different tax methods in a cross-border shopping model with monopolistic competition. Here, we compared the short-run and long-run outcomes and clarified the impact of consumer mobility. The main findings are as follows. First, the tax effects on a shortrun equilibrium support the standard argument obtained in monopoly analysis, shown in Aiura and Ogawa (2013), that the ADV tax method leads to higher tax revenue for governments than the unit tax method does. Second, tax revenue from an ADV tax competition remains greater than that of a unit 
tax competition under a free-entry, long-run equilibrium. This result confirms the efficacy of the ADV tax method not only in the short run but also in the long run. Comparing short-run and long-run tax revenues reveals that the $\mathrm{ADV}$ tax method loses some of its advantage in the long run and that the tax-revenue gap between the two methods in the long run is smaller than that in the short run. This is because the government has a stronger incentive to set a lower ADV tax rate to increase the equilibrium number of firms (i.e., variety) in the long run but no such incentive in the short run, because the number of firms is fixed. This leads governments to choose a lower ADV tax rate in the long run, which decreases the tax-revenue gap between the ADV tax and the unit tax. Our findings on the tax-revenue gap are summarized in table 3, which reveals that as consumer mobility increases (i.e., reading down the columns of the table), the tax-revenue gap between the ADV tax and the unit tax decreases. Furthermore, reading across the rows of the open-border case, we find that firms' entry also reduces the tax-revenue gap between the ADV tax and the unit tax.

In section 4, we examined the robustness of the results by extending the model to the case of a welfare-maximizing government. The extension reveals that the governments subsidize firms to attract consumers and to enter the market. In addition, when the government chooses a tax/subsidy rate to maximize domestic welfare, the two tax methods are welfare-indifferent in the short run but the ADV subsidy is welfare-superior in the long run. This result implies that the entry of firms increases the dominance of the ADV method, which contrasts with the finding in the case of the revenue-maximizing government in which the entry of firms weakens the superiority of the ADV method in terms of raising the tax revenue.

The findings on the welfare gap are summarized in table 4, which shows that opening the borders increases the welfare gap in the long run. This again contrasts with the finding in the case of a revenuemaximizing government in which border openings reduce the revenue gap in the long run. Hence, a reduction in transport costs influences the gaps in tax revenue and in welfare in opposite directions.

Lastly, we refer to a topic that is yet to be analyzed. In this study, we compared the outcomes in the short run and long run by assuming that both countries use the same tax method when competing for mobile consumers. It is natural to assume that all countries use the same tax method in a model of symmetric countries. However, this approach might be inadequate when analyzing an endogenous tax method choice. An analysis of the equilibrium outcome when two governments use a different tax method would contribute to the literature on the endogenous choice of tax methods. An analysis using simulation techniques would solve this problem.

\section{Appendix}

A. Eq. (23). Substituting (8) into (9) and differentiating with respect to $t_{j}$, we obtain

$$
\frac{d n_{j}}{d t_{j}}=\frac{\mu}{\sigma f}\left[\frac{\mu}{2 \tau}\left(\frac{1}{c+t_{j}}+\frac{1}{(\sigma-1) n_{j}} \frac{d n_{j}}{d t_{j}}\right)\right]
$$




\begin{tabular}{ccc}
\hline & Short run & Long run \\
\hline Closed border & +++ & +++ \\
Open border & ++ & + \\
\hline
\end{tabular}

Table 3. Tax-revenue gap between ADV tax and unit tax competition

Note. A larger + indicates a greater tax-revenue gap.

\begin{tabular}{ccc}
\hline & Short run & Long run \\
\hline Closed border & 0 & + \\
Open border & 0 & ++ \\
\hline
\end{tabular}

Table 4. Welfare gap between ADV tax and unit tax competition

Note. A larger + means a greater welfare gap.

Using (9), we can rewrite this as

$$
\frac{d n_{j}}{d t_{j}}=\frac{\mu}{\sigma f}\left[\frac{\mu}{2 \tau}\left(\frac{1}{c+t_{j}}+\frac{\sigma f}{\mu(\sigma-1) l_{j}} \frac{d n_{j}}{d t_{j}}\right)\right] .
$$

Solving for $d n_{j} / d t_{j}$, we have

$$
\frac{d n_{j}}{d t_{j}}=-\frac{\mu(\sigma-1)}{\left[2 \tau(\sigma-1) l_{j}-\mu\right]\left(c+t_{j}\right)} \cdot \frac{\mu l_{j}}{\sigma f} .
$$

Here, $r_{i}=0$. Then, from $(9),\left(\mu l_{j}\right) /(\sigma f)=n_{j}$. Using this condition, we obtain $(23)$.

B. Stability Condition. The number of firms in the long-run equilibrium, $\tilde{n}_{j}$, satisfies (9). From

$$
\frac{\partial \pi_{j}}{\partial n_{j}}=\frac{\left(1-r_{j}\right) \mu}{n_{j}^{2} \sigma}\left(\frac{\mu}{2 \tau(\sigma-1)}-l_{j}\right),
$$

we find that the long-run equilibrium is unstable when $2 \tau(\sigma-1) l_{j}\left(\tilde{n_{j}}\right)<\mu$ because $\partial \pi_{j}\left(\tilde{n_{j}}\right) / \partial n_{j}>0$, demonstrating that the stability of the long-run equilibrium is ensured if $2 \tau(\sigma-1)>\mu$ in the symmetric equilibrium, $l_{j}\left(\tilde{n_{j}}\right)=1$. If Assumption 1 is violated and $2 \tau(\sigma-1)-\mu \leq 0$ holds, $d R_{j}^{U} / d t_{j}>0$ and $\lim _{t_{j} \rightarrow \infty} d R_{j}^{U} / d t_{j}=0$ in the range of $0 \leq t_{1}=t_{2}<\infty$. In this case, the analysis is irrelevant because the equilibrium tax rate is $t_{1}=t_{2}=\infty$, under which the tax revenue amount is the same as that in the absence of cross-border shopping.

C. Eq. (27). Substituting (8) into (9) and differentiating with respect to $r_{j}$, we have

$$
\frac{d n_{j}}{d r_{j}}=-\frac{\mu l_{j}}{\sigma f}+\frac{\mu\left(1-r_{j}\right)}{\sigma f}\left[\frac{\mu}{2 \tau}\left(-\frac{1}{1-r_{j}}+\frac{1}{(\sigma-1) n_{j}} \frac{d n_{j}}{d r_{j}}\right)\right] .
$$

Substituting (9) into $n_{j}$, we can rewrite it as 


$$
\frac{d n_{j}}{d r_{j}}=-\frac{\mu l_{j}}{\sigma f}+\frac{\mu\left(1-r_{j}\right)}{\sigma f}\left[\frac{\mu}{2 \tau}\left(-\frac{1}{1-r_{j}}+\frac{\sigma f}{\mu(\sigma-1) l_{j}\left(1-r_{j}\right)} \frac{d n_{j}}{d r_{j}}\right)\right] .
$$

Solving for $d n_{j} / d r_{j}$, we obtain

$$
\frac{d n_{j}}{d r_{j}}=-\frac{\left(2 \tau l_{j}+\mu\right)(\sigma-1)}{\left[2 \tau(\sigma-1) l_{j}-\mu\right]} \cdot \frac{\mu l_{j}}{\sigma f} .
$$

From $(9),\left(\mu l_{j}\right) /(\sigma f)=n_{j} /\left(1-r_{j}\right)$. Using this equation, we have (27).

D. Proof of Proposition 3. A comparison gives

$$
\begin{aligned}
\left(\hat{R}^{A C}-\hat{R}^{U C}\right) & -\left(\hat{R}^{A O}-\hat{R}^{U O}\right) \\
& =\frac{\mu}{\sigma}-\frac{2 \tau \mu}{\sigma(2 \tau+\mu)}=\frac{\mu^{2}}{\sigma(2 \tau+\mu)}>0, \\
\left(\tilde{R}^{A C}-\tilde{R}^{U C}\right) & -\left(\tilde{R}^{A O}-\tilde{R}^{U O}\right) \\
& =\frac{\mu}{\sigma}-\frac{[2(\sigma-1) \tau-\mu]^{2} \mu}{\sigma(\sigma-1)(2 \tau+\mu)[(\sigma-1)(2 \tau+\mu)-\mu]} \\
& =\frac{(2(\sigma-1)+1)(2 \tau(\sigma-1)-\mu)+\sigma \mu(\sigma-1)}{\sigma(2 \tau+\mu)(\sigma-1)((\sigma-1)(2 \tau+\mu)-\mu)} \mu^{2}>0 .
\end{aligned}
$$

The inequalities stem from $\sigma>1$ and Assumption 1.

E. Proof of Proposition 4. Inserting equilibrium tax rates into the indirect welfare function in the short run, we have

$$
\begin{aligned}
\hat{W}^{U C} & =\int_{0}^{1} U(x) d x+R+n \pi \\
& =I-\mu\left[1+\ln \left(\frac{\sigma-1}{\sigma} c\right)-\frac{\ln n}{\sigma-1}\right]-\int_{0}^{1} F(x) d x-n f \\
& =\hat{W}^{A C}
\end{aligned}
$$

which proves that $\hat{W}^{U C}=\hat{W}^{A C}$. In a similar manner, we insert the equilibrium tax rates into the indirect welfare function in the long run to obtain

$$
\begin{aligned}
\tilde{W}^{U C} & =\int_{0}^{1} U(x) d x+R \\
& =I-\frac{\mu}{\sigma}-\mu\left[1+\ln \left(\frac{\sigma-1}{\sigma} c\right)-\frac{1}{\sigma-1} \ln \frac{\mu}{\sigma f}\right]-\int_{0}^{1} F(x) d x \\
\tilde{W}^{A C} & =\int_{0}^{1} U(x) d x+R \\
& =I-\frac{\mu}{\sigma-1}-\mu\left[1+\ln \left(\frac{\sigma-1}{\sigma} c\right)-\frac{1}{\sigma-1} \ln \frac{\mu}{(\sigma-1) f}\right]-\int_{0}^{1} F(x) d x .
\end{aligned}
$$


A comparison shows that

$$
\tilde{W}^{A C}-\tilde{W}^{U C}=\frac{\mu}{\sigma(\sigma-1)}\left(\sigma \ln \frac{\sigma}{\sigma-1}-1\right)>0 .
$$

F. Proof of Lemma 3. Substituting the equilibrium tax rates into the government's objective function, we obtain the domestic welfare as

$$
\begin{aligned}
\hat{W}^{A O} & =\int_{0}^{1} U(x) d x+R+n \pi \\
& =I-\mu\left[1+\ln \left(\frac{\sigma-1}{\sigma} \mu c\right)-\frac{\ln n}{\sigma-1}\right]-\int_{0}^{1} F(x) d x-n f \\
& =\hat{W}^{U O},
\end{aligned}
$$

which is identical to (35), proving that $\hat{W}^{U O}=\hat{W}^{A O}=\hat{W}^{U C}=\hat{W}^{A C}$ holds.

\section{References}

Aiura, H. and Ogawa, H. (2013), Unit tax versus ad valorem tax: A tax competition model with cross-border shopping, Journal of Public Economics, vol.105, 30-38.

Anderson, S.P., de Palma, A., and Kreider, B. (2001), Tax incidence in differentiated product oligopoly, Journal of Public Economics, vol.81, 173-192.

Akai, N., Ogawa, H., and Ogawa, Y. (2011), Endogenous choice on tax instruments in a tax competition model: Unit tax versus ad valorem tax, International Tax and Public Finance, vol.18, 495-506.

Akai, N., Ogawa, H., and Ogawa, Y. (2014), Endogenous choice of subsidy instruments in imperfectly competitive markets: A unit subsidy versus an ad valorem subsidy, Annals of Economics and Statistics/Annales d'économie et de statistique, forthcoming.

Blackorby, C. and Murty, S. (2007), Unit versus ad valorem taxes: Monopoly in general equilibrium, Journal of Public Economics, vol.91, 817-822.

Brander, J. A. and Spencer, B. J. (1985), Export subsidies and international market share rivalry, Journal of International Economics, vol.18, 83-100.

Delipalla, S. and Keen, M. (1992), The comparison between ad valorem and specific taxation under imperfect competition, Journal of Public Economics, vol.49, 351-367.

Denicoló, V. and Matteuzzi, M. (2000), Specific and ad valorem taxation in asymmetric Cournot oligopolies, International Tax and Public Finance, vol.7, 335-342.

Dixit, A. and Stiglitz, J. (1977), Monopolistic competition and optimum product diversity, American Economic Review, vol.67, 297-308. 
Dröge, S. and Schröder, P. (2009), The welfare comparison of corrective ad valorem and unit taxes under monopolistic competition, International Tax and Public Finance, vol.16, 164-175.

Hamilton, S.F. (2009), Excise taxes with multiproduct transactions, American Economic Review, vol.99, $458-471$.

Henkel, J., Konrad, S., and Walz, U. (2000), Coalition building in a spatial economy, Journal of Urban Economics, vol.47, 136-163.

Jorgensen, J. and Schröder, P. (2005), Welfare-ranking ad valorem and specific tariffs under monopolistic competition, Canadian Journal of Economics, vol.38, 228-241.

Kanbur, R. and Keen, M. (1993), Jeux Sans Frontieres: Tax competition and tax coordination when countries differ in size, American Economic Review, vol.83, 877-892.

Keen, M. (1998), The balance between specific and ad valorem taxation, Fiscal Studies, vol.19, 1-37.

Kind, H.J., Koethenbuerger, M., and Schjelderup, G. (2009), On revenue and welfare dominance of ad valorem taxes in two-sided markets, Economics Letters, vol.104, 86-88.

Lapan, H.E. and Hennessy, D.A. (2011), Unit versus ad valorem taxes in multiproduct Cournot oligopoly, Journal of Public Economic Theory, vol.13, 125-138.

Lockwood, B. (2004), Competition in unit vs. ad valorem taxes, International Tax and Public Finance, vol.11, 763-772.

Lockwood, B. and Wong, K. (2000), Specific and ad valorem tariffs are not equivalent in trade wars, Journal of International Economics, vol.52, 183-195.

Myles, G. (1996), Imperfect competition and the optimal combination of ad valorem and specific taxation, International Tax and Public Finance, vol.3, 29-44.

Nielsen, S.B. (2001), A simple model of commodity taxation and cross-border shopping, Scandinavian Journal of Economics, vol.103, 599-623.

Nielsen, S.B. (2002), Cross-border shopping from small to large countries, Economics Letters, vol.77, 309-313.

Ohsawa, Y. (1999), Cross-border shopping and commodity tax competition among governments, Regional Science and Urban Economics, vol.29, 33-51.

Salanié, B. (2002), The Economics of Taxation, MIT Press.

Scharf, K.A. (1999), Scale economies in cross-border shopping and commodity taxation, International Tax and Public Finance, vol.6, 89-99. 
Schröder, P.J.H., and Sørensen, A. (2010), Ad valorem versus unit taxes: Monopolistic competition, heterogeneous firms, and intra-industry reallocations, Journal of Economics, vol.101, 247-265.

Schröder, P.J.H. (2004), The comparison between ad valorem and unit taxes under monopolistic competition, Journal of Economics, vol.83, 281-292.

Skeath, A. and Trandel, G. (1994), A Pareto comparison of ad valorem and unit taxes in noncompetitive environments, Journal of Public Economics, vol.53, 53-71.

Suits, D. and Musgrave, R. (1953), Ad valorem and unit taxes compared, Quarterly Journal of Economics, vol.67, 598-604.

Takatsuka, H. (2013), Tax effects in a two-region model of monopolistic competition, Papers in Regional Science, in press.

Vetter, H. (2013), Consumption taxes in monopolistic competition: A comment, Journal of Economics, vol.110, 287-295.

Wang, Y-Q. (1999), Commodity taxes under fiscal competition: Stackelberg equilibrium and optimality, American Economic Review, vol.89, 974-981. 